\title{
REVIEW
}

\section{Adherence to Oral and Topical Medications in Cutaneous Lupus Erythematosus is not Well Characterized}

\author{
Michael E. Farhangian · William W. Huang $\cdot$ Steven R. Feldman
}

To view enhanced content go to www.dermtherapy-open.com

Received: March 19, 2015 / Published online: April 22, 2015

(c) The Author(s) 2015. This article is published with open access at Springerlink.com

\section{ABSTRACT}

Introduction: Treatment adherence plays a large role in chronic dermatologic diseases and may play an important role in the outcomes of patients with cutaneous lupus erythematosus (CLE). We sought to gauge what is currently known about adherence to topical and oral medications in patients with CLE.

Methods: A review of MEDLINE was performed using a combination of the phrases "adherence", "compliance", "lupus", and "cutaneous". Studies were hand searched and prospective and cross-sectional studies

Electronic supplementary material The online version of this article (doi:10.1007/s13555-015-0075-4) contains supplementary material, which is available to authorized users.

M. E. Farhangian $(\bowtie) \cdot$ W. W. Huang

Department of Dermatology, Center for

Dermatology Research, Wake Forest School of

Medicine, Winston-Salem, NC, USA

e-mail: mfarhang@wakehealth.edu

\section{S. R. Feldman}

Department of Pathology, Wake Forest School of

Medicine, Winston-Salem, NC, USA

S. R. Feldman

Department of Public Health Sciences, Wake Forest

School of Medicine, Winston-Salem, NC, USA evaluating medication adherence in patients with CLE and systemic lupus erythematosus (SLE) were included.

Results: Only two articles explored adherence in patients with CLE, while 17 articles discussed treatment adherence in patients with SLE. Depression was consistently cited as detrimental to adherence. The impact that race, ethnicity, and education has on adherence is unclear. Three studies noted a clear connection between adherence and disease activity, while two others did not. Few studies investigated methods that have improved adherence to treatment which have showed promise.

Conclusion: Much of what we know about adherence to medication in patients with lupus is limited to SLE. Although cutaneous symptoms are among the most common manifestations of SLE, cutaneous disease is often managed at least in part with topical agents, and adherence to topical treatment was not assessed in any of the articles, though one study investigated sunscreen usage in patients with CLE. Understanding adherence in patients with CLE may help contribute to better CLE treatment outcomes. 
Keywords: Adherence;

Corticosteroids;

Cutaneous

Compliance;

lupus

erythematosus (CLE); Hydroxychloroquine;

Sunscreen; Systemic lupus erythematosus (SLE); Topical medications

\section{INTRODUCTION}

Cutaneous lupus erythematosus (CLE) is a chronic dermatologic disease that frequently requires long-term treatment and follow-up. Patients with CLE suffer from scarring, dyspigmentation, erythema, scaling, itching, burning, and pain which can have a profoundly detrimental impact on quality of life (QoL) [1]. Although there is no current Food and Drug Administration approved treatment for CLE, managing these patients is generally quite complex, consisting of lifestyle modifications [2] coupled with topical and/or oral medications [3]. Patient adherence in chronic diseases is a critical problem, as adherence to medication decreases through the long course of illness and may be adversely affected by the complexity of treatment [4-6]. Poor adherence may result in poor treatment outcomes [7-9].

We reviewed the literature to gauge what is currently known about adherence to treatment in patients with CLE. However, since approximately $85 \%$ of patients with systemic lupus erythematosus (SLE) will suffer from cutaneous manifestations of the disease at some point [10], and since American College of Rheumatology SLE criteria can be made on the basis of cutaneous disease alone [11], we also included studies involving patients with SLE. The purpose of this study is to determine what is known about adherence to treatment in patients with CLE and SLE (with cutaneous disease) and to identify gaps in the current knowledge of adherence in patients with CLE to guide future research endeavors to improve patient adherence.

\section{METHODS}

A search of MEDLINE was performed from date of inception to March 2015 using a combination of the search terms: "adherence", "compliance", "lupus", and "cutaneous". The results of these searches were filtered to include prospective and cross-sectional studies examining patient adherence to medications in both CLE and SLE. Duplicate articles and those not available in English were excluded. Studies on SLE that focused on the impact of the non-cutaneous aspects of SLE (e.g., kidney failure, antiphospholipid syndrome) on patient adherence, and those that also focused on adherence in other diseases in addition to CLE or SLE were excluded to maintain a focus on cutaneous disease. The studies were screened through titles, after which articles of interest were further examined through abstracts. If the study was found to be potentially eligible after examination of the abstract, a full-text review was carried out to assess for inclusion.

This article is based on previously conducted studies and does not involve any new studies of human or animal subjects performed by any of the authors.

\section{RESULTS}

A total of 19 studies met the inclusion criteria (Table 1). Only one article [12] explored treatment adherence in patients with CLE, while another study examined adherence to sunscreen in patients with CLE [13]. The remaining 17 articles discussed treatment adherence in patients with SLE. Among these 


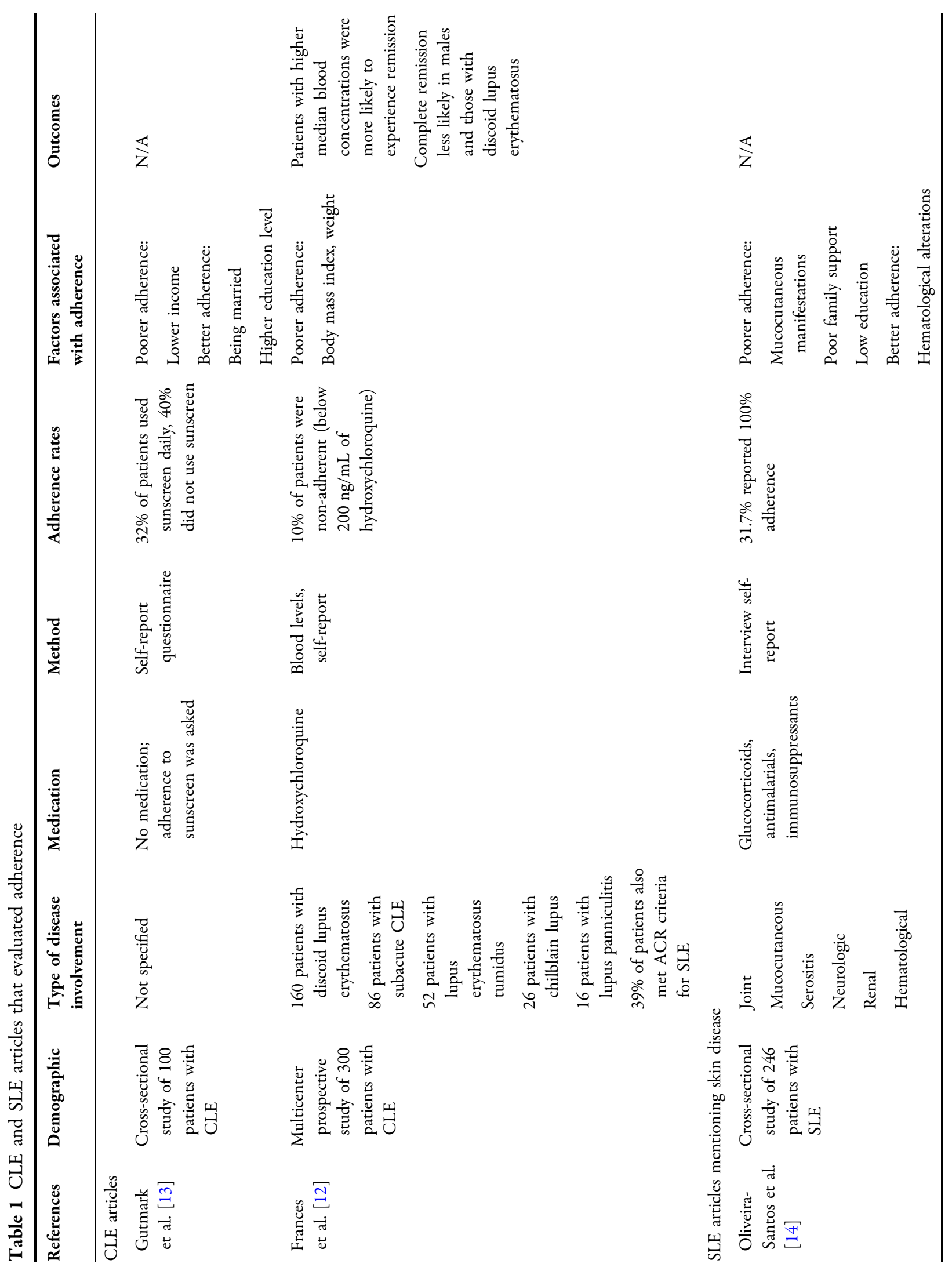




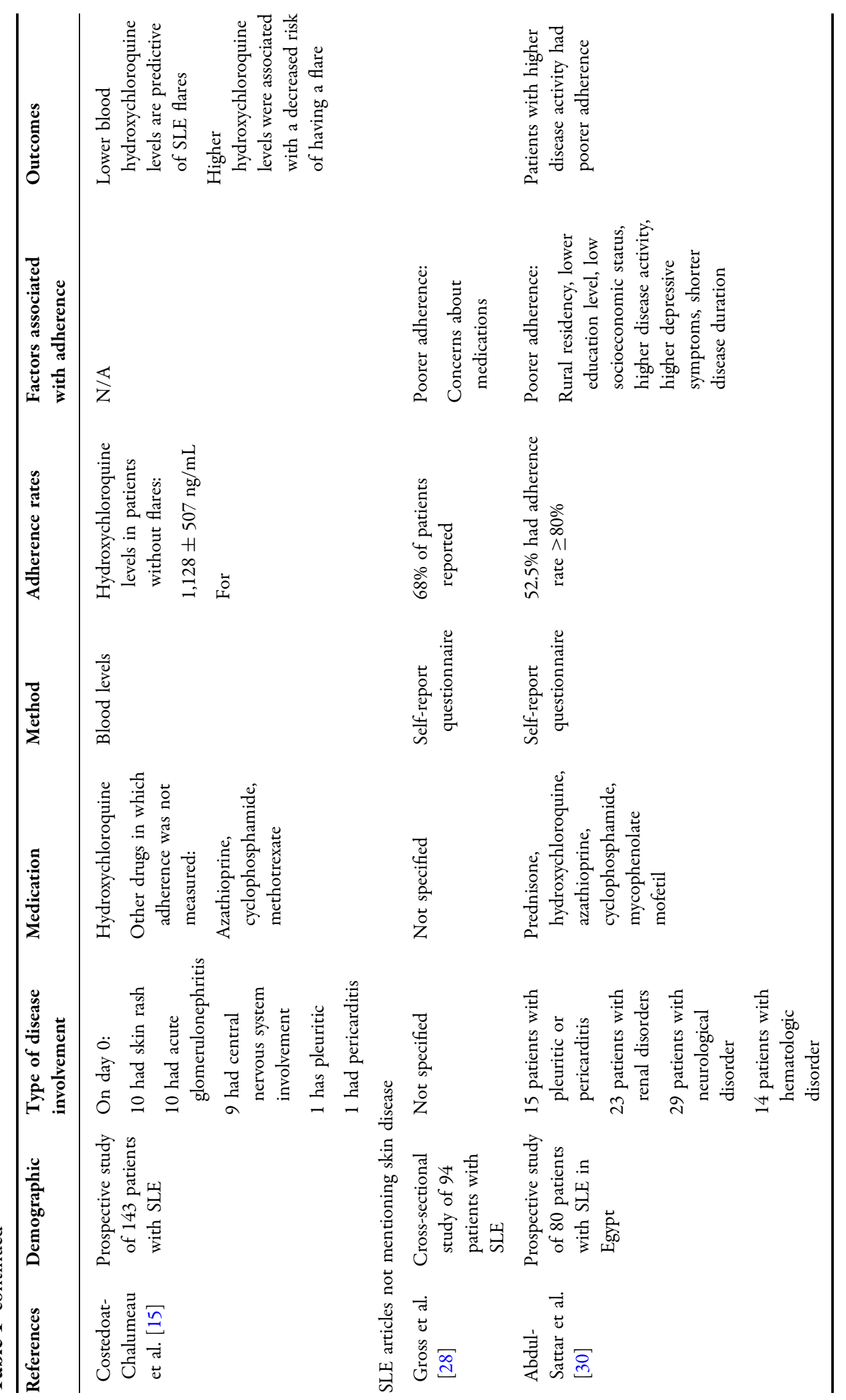




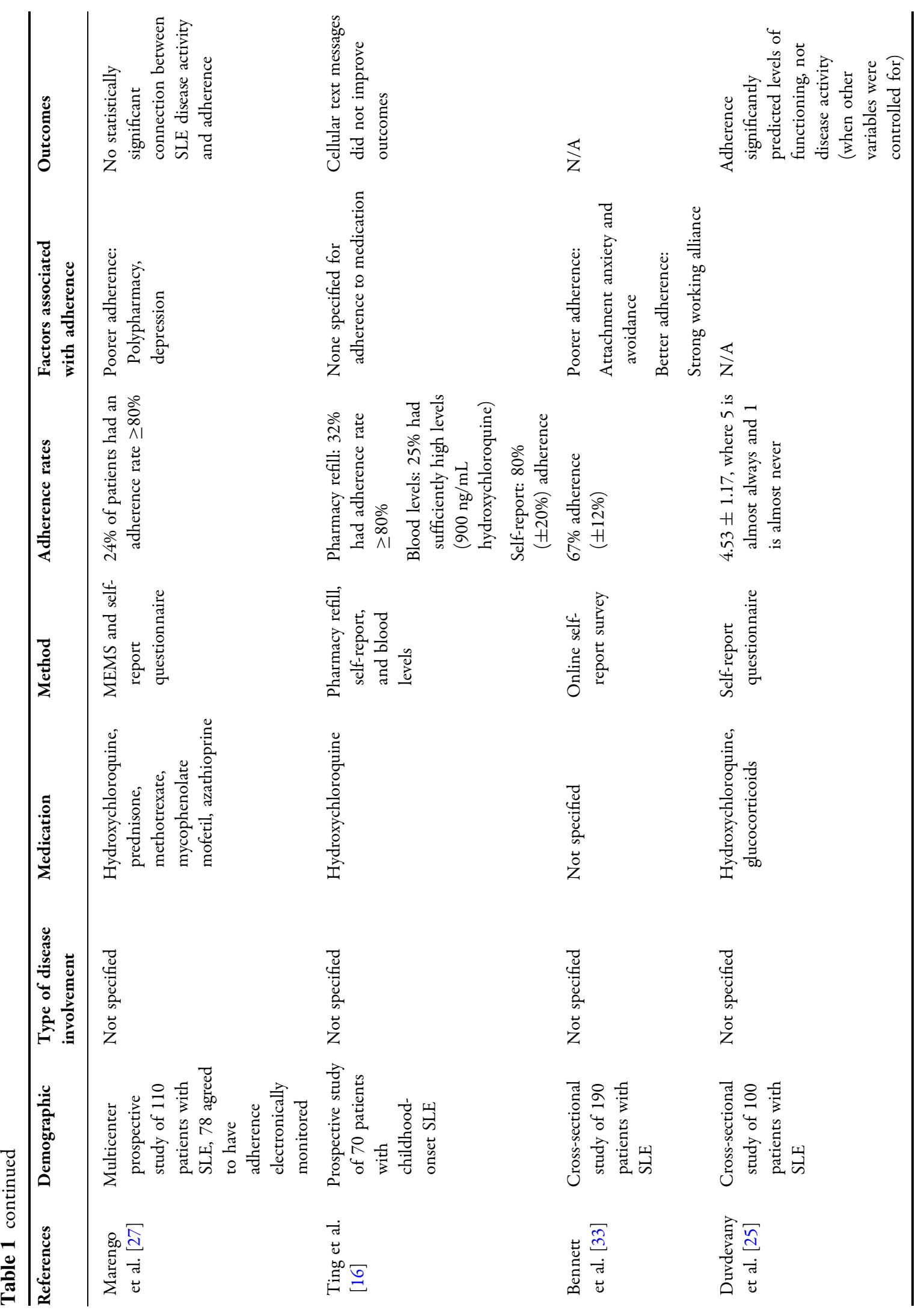




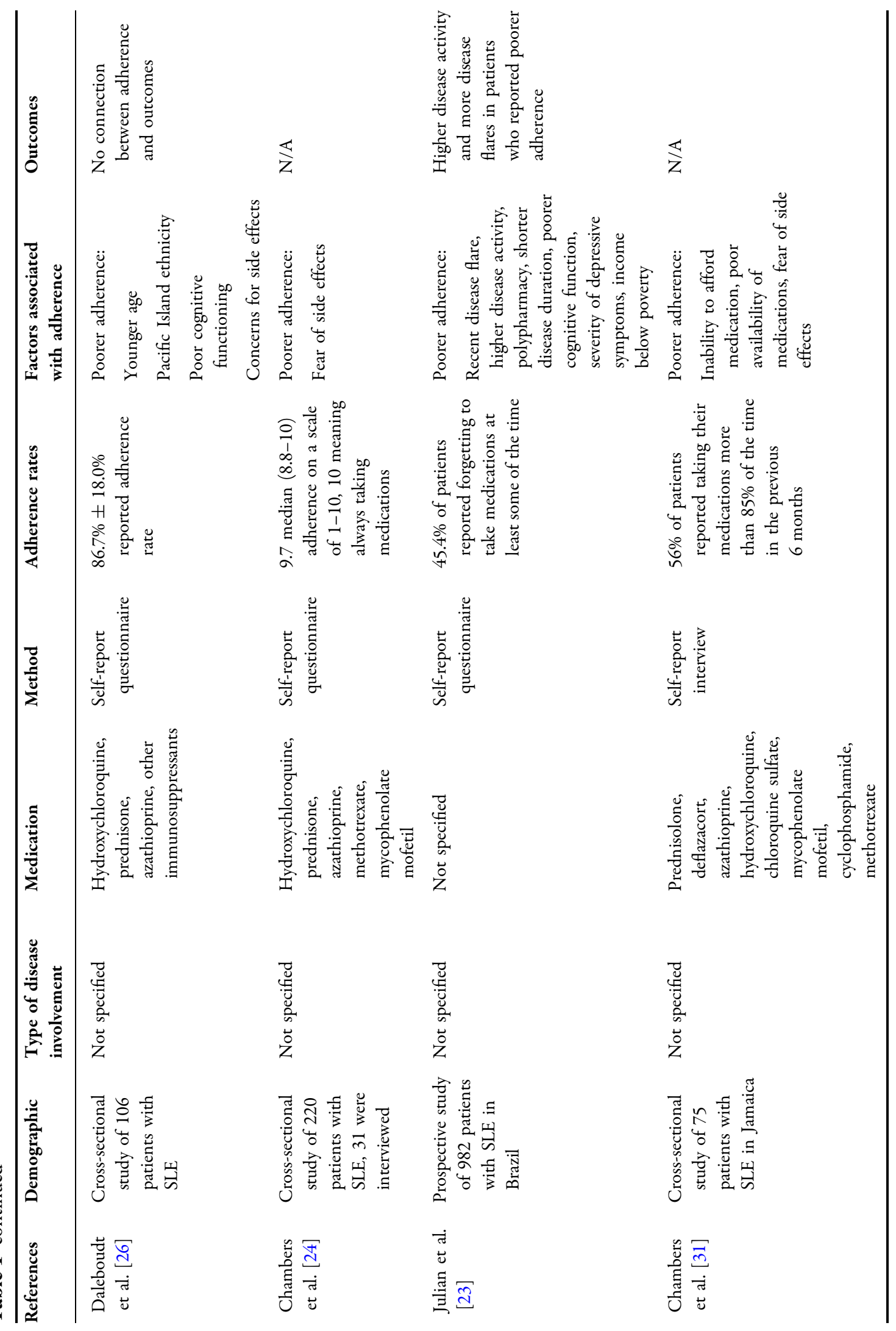




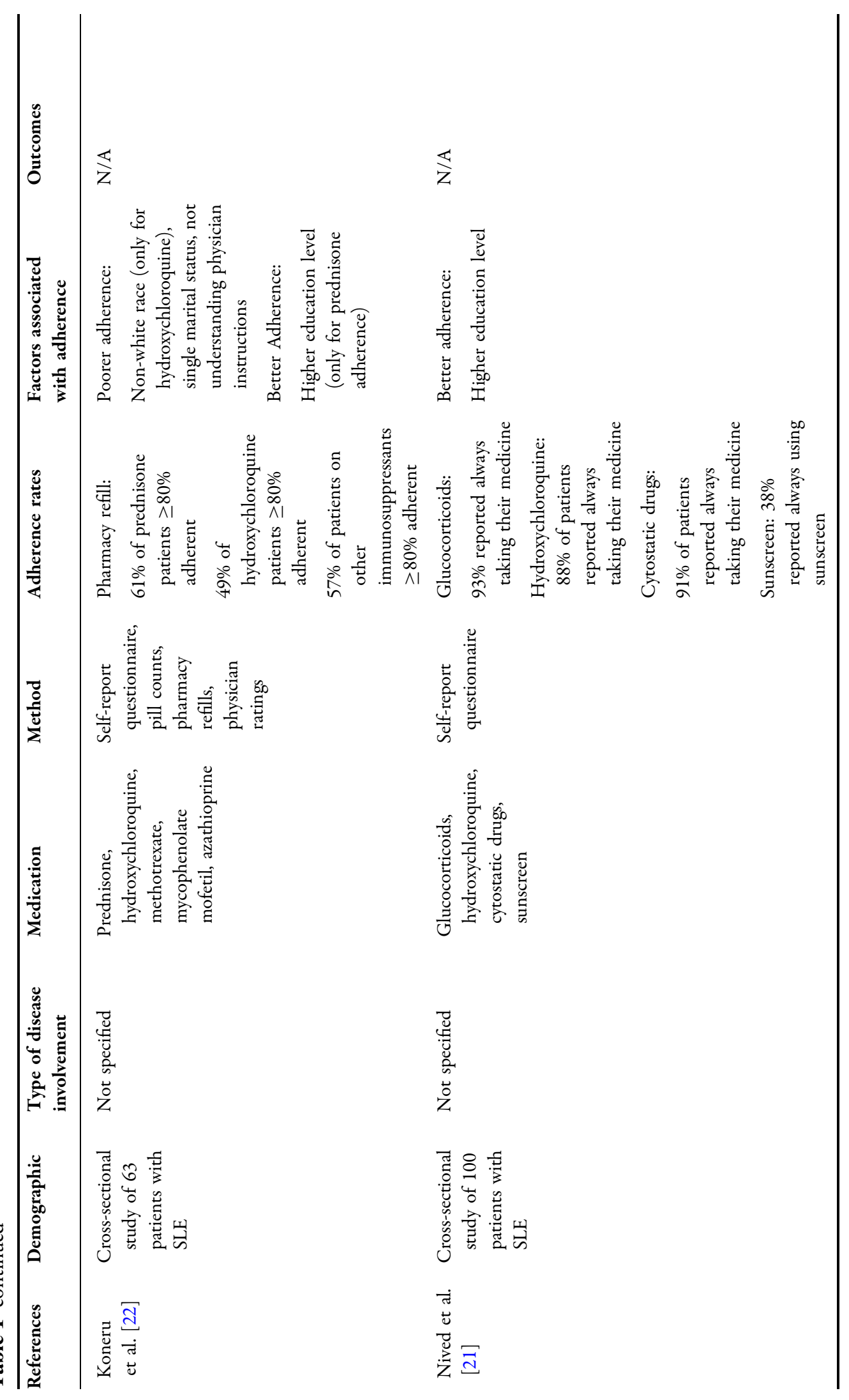




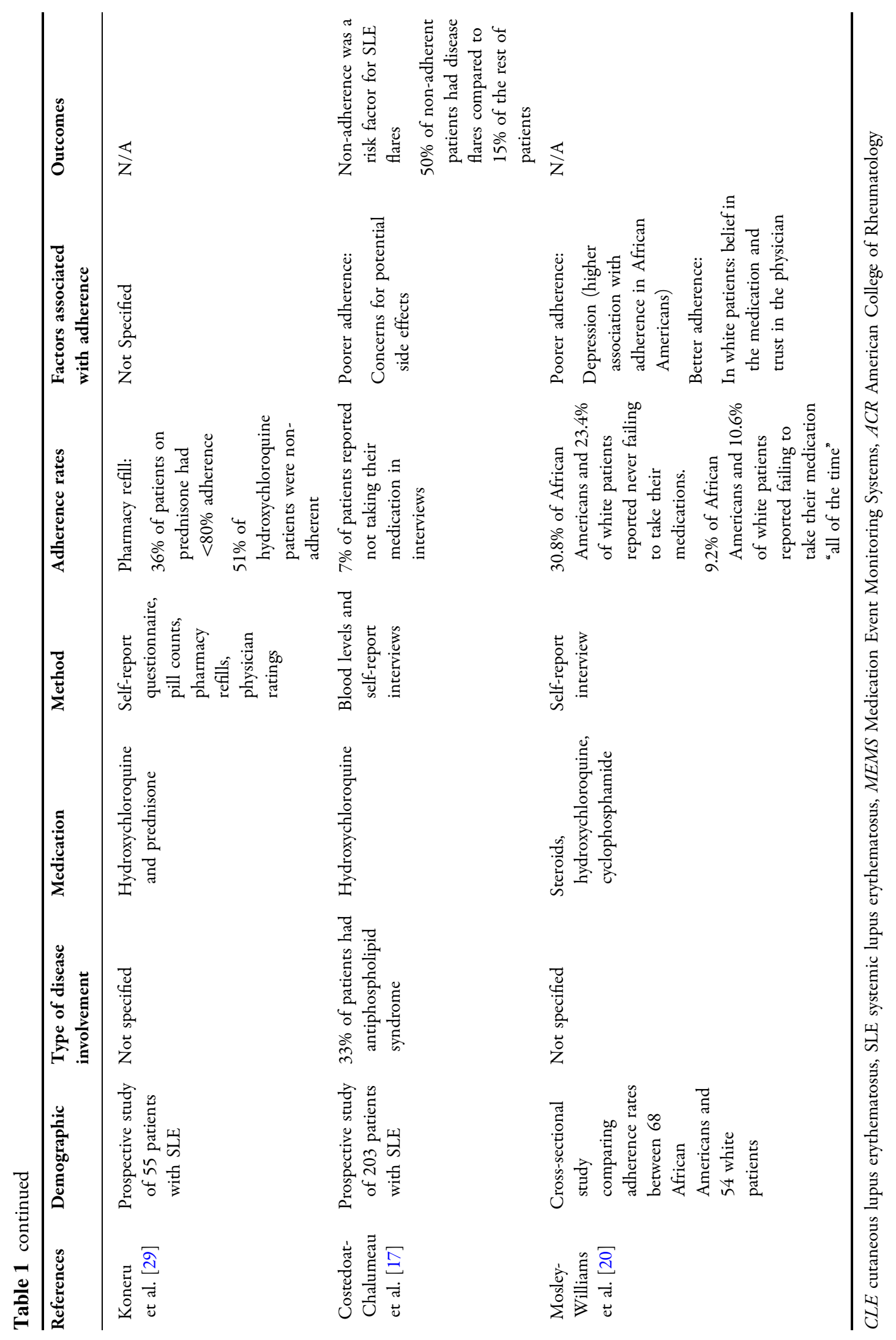


studies, only two specifically mentioned skin manifestations [14, 15].

\section{Measuring Adherence in Lupus Erythematosus}

A large contributor toward the wide range of adherence rates observed in these studies (Table 1) was likely due to the different methods used to assess adherence (Table 2). The different methods can be characterized as either subjective (e.g., self-report) or objective (e.g., drug blood assays, electronic monitoring). Measuring hydroxychloroquine blood concentration is an objective method that has been employed by several studies used to determine adherence levels in SLE and CLE patients [12, 16, 17]. Objective assessments of adherence are preferred, since patients often overestimate their own adherence [18]. However, Ting et al. [16] used several methods to assess adherence, and noted that selfreported adherence correlated with adherence based on hydroxychloroquine blood concentration and adherence assessed through pharmacy refill data.

One challenge that is encountered when assessing adherence through blood assays is

Table 2 Advantages and disadvantages of the methods used to determine adherence in SLE and CLE

\begin{tabular}{|c|c|c|c|c|c|}
\hline \multicolumn{6}{|c|}{ Methods of measuring adherence in CLE and SLE } \\
\hline & MEMS & $\begin{array}{l}\text { Hydroxychloroquine } \\
\text { blood assays }\end{array}$ & $\begin{array}{l}\text { Pharmacy } \\
\text { refill } \\
\text { information }\end{array}$ & Pill counting & Self-report \\
\hline \multirow[t]{2}{*}{ Pros } & $\begin{array}{l}\text { Can be used on topical and } \\
\text { oral medications }\end{array}$ & $\begin{array}{l}\text { Accurate in } \\
\text { recognizing non- } \\
\text { adherent patients } \\
{[17]}\end{array}$ & Inexpensive & Inexpensive & Inexpensive \\
\hline & $\begin{array}{l}\text { Provides exact date and time } \\
\text { medication was opened [27] }\end{array}$ & & & & \\
\hline \multirow[t]{3}{*}{ Cons } & Expensive [29] & $\begin{array}{l}\text { Not readily available } \\
\text { [29] }\end{array}$ & $\begin{array}{l}\text { Time } \\
\text { consuming } \\
{[29]}\end{array}$ & $\begin{array}{l}\text { Cumbersome } \\
\text { [29] }\end{array}$ & Subjective \\
\hline & $\begin{array}{l}\text { Patients may not use } \\
\text { medication even if they open } \\
\text { the bottle which can } \\
\text { overestimate adherence [27] }\end{array}$ & $\begin{array}{l}\text { Occasional missed } \\
\text { doses may not be } \\
\text { noticed because of } \\
\text { long half-life }\end{array}$ & & & $\begin{array}{l}\text { Doctors and } \\
\text { patients } \\
\text { overestimate } \\
\text { adherence } \\
\text { levels [29] }\end{array}$ \\
\hline & & $\begin{array}{l}\text { Cannot be used for } \\
\text { topical medications }\end{array}$ & $\begin{array}{l}\text { Cannot be } \\
\text { used for } \\
\text { topical } \\
\text { medications }\end{array}$ & $\begin{array}{l}\text { Cannot be } \\
\text { used for } \\
\text { topical } \\
\text { medications }\end{array}$ & \\
\hline $\begin{array}{l}\text { Useful } \\
\text { applications }\end{array}$ & Research & $\begin{array}{l}\text { Research or clinical } \\
\text { practice }\end{array}$ & Research & Research & $\begin{array}{r}\text { Survey studies or } \\
\text { clinical practice }\end{array}$ \\
\hline
\end{tabular}

$C L E$ cutaneous lupus erythematosus, SLE systemic lupus erythematosus, MEMS Medication Event Monitoring Systems 
that adherence tends to increase closer to when the patient's appointment is, the so-called "white coat compliance" [17, 19]. However, hydroxychloroquine has an exceptionally long 40 day half-life and small inter-day variation in blood levels, which allows physicians to assess long-term adherence to the medication with reasonable accuracy [12, 17]. Furthermore, unscheduled blood-level measurements have been also used to circumvent the issue of white coat compliance [17]. Unfortunately, few drugs have such a long half-life that would enable practitioners to know with confidence if their patients are truly adhering to the medication, making this not applicable for other systemic medications used to treat CLE or cutaneous disease in SLE.

Additional methods of measuring medication adherence in SLE included physician and patient questionnaires or ratings, pill counting, Medication Event Monitoring Systems (MEMS), and using pharmacy refill information $[14,20-28]$. The use of MEMS is an objective method of assessing patient adherence to medications in SLE, which uses microchips to determine when patients have opened and closed their medication bottles [22, 27]. MEMS can be used for topical medications as well as oral medications, which allows for its utilization in topical treatments for SLE and CLE, which cannot be done in methods such as blood assays or pharmacy refill information [6].

Pill counting involves patients bringing in their medication to their appointments and subsequently having their remaining pills counted to determine their level of adherence. Acquiring pharmacy refill data can show the level of patient adherence by seeing if patients are refilling their medications in a timely manner. One study utilized multiple methods including blood assays of hydroxychloroquine, questionnaires, and pharmacy refill information to better assess adherence in adolescent patients with SLE [16]. Pharmacy refill information has also been used as the criterion standard to base the accuracy of other methods of measuring adherence, such as patient and physician questionnaires, and pill counts [29]. Of these methods, pill counting was the least effective in determining adherence [29]. Using pharmacy refill information to determine adherence to topical medications would also prove challenging, because patients may use varying amounts of medication depending on the extent of cutaneous disease they have. While there are numerous ways of assessing adherence, MEMS appear to be the most ideal for clinical trials, whereas pharmacy refill information strikes a good balance between cost, practicality, and objectivity, making it a good choice for more mainstream use.

\section{Factors Contributing to Non-Adherence}

Many factors have been postulated to have an impact on treatment adherence in patients with SLE and CLE (Table 1). The impact that race/ ethnicity has on medication adherence in SLE is controversial. Two studies noted no statistically significant difference in adherence to medication between white patients and ethnic minorities suffering from SLE. One study in Brazil [14] noted that white race was a factor that improved adherence, while others found that non-white race was a risk factor for lower adherence to hydroxychloroquine $[14,20,22$, 27]. While race and ethnicity have not been definitively shown to impact adherence to medication in SLE, socioeconomic factors can contribute [30]. Affordability of medication can also play a large role in adherence [31].

Different factors may play a role in adherence to medication between white and black patients. There was a substantial disparity 
in income between the groups, and the differences between the groups' reasons for poor adherence to medication were eliminated after controlling for income level [20]. Education level was another factor that may have an effect on medication adherence in patients with SLE, with lower levels of education thought to result in poorer adherence to medication [14, 22-24, 30]. However, lower education levels were associated with worse adherence to medication in only two of five studies $[14,22]$. In a study of CLE patients, Gutmark et al. [13] noted that adherence to sunscreen was better in patients that had a higher educational level, and lower in patients with lower income. Conversely, another study noted that higher education levels and those with lower income levels were associated with lower levels of adherence, although the population in this study were all of low socioeconomic status [28]. Depression is a consistent factor that negatively impacts adherence to medication in SLE $[20,23,25$, 27, 30]. SLE is thought to directly cause depression either by its direct impact on the brain and/or due to the chronic inflammatory process [32]. Furthermore, depression, as well as other neuropsychiatric manifestations of SLE, can cause cognitive impairment which can lead to patients forgetting to take their medications $[23,26]$. Many other reasons contribute to poor adherence to medication in patients with SLE (Table 1).

\section{Adherence, Disease Activity, and Outcomes}

Poor adherence to medication can result in poor outcomes in patients with SLE, as it is associated with increased disease activity as well as increased risk of disease flares [15, 17, 23, 30]. Patients with SLE who struggled with adhering to their medications had a decreased level of functioning [23]. Presumably, poor adherence to treatment leads to increased disease activity which can profoundly decrease functioning. Increased disease activity was not only a result of poor adherence, but also a risk factor to it [17, 23]. Higher blood levels of hydroxychloroquine led to higher levels of remission in patients with CLE, implying that increased adherence in these patients was associated with better outcomes [12].

While there is likely a clear association between adherence and outcomes, a couple of studies did not find this connection. Marengo et al. [27] noted that while their patients improved after 2 years of adherence monitoring, there was no statistically significant association between adherence and SLE disease activity. Daleboudt et al. [26] found no connection between disease severity and self-reported adherence rates.

\section{Methods used to Improve Adherence}

Several studies examined ways of improving adherence in patients with SLE. One barrier to treatment adherence in patients with SLE, and adherence to sunscreen in patients with CLE is forgetfulness [13, 23]. One study attempted to overcome this using cellular text messaging to remind patients with childhood-onset SLE to take their medications; however, there was no improvement in adherence to treatment noted among the adolescents studied [16]. Hydroxychloroquine blood levels were utilized to identify patients who were non-adherent to hydroxychloroquine and found that confronting these patients with their nonadherence and counseling them regarding the characteristics of hydroxychloroquine treatment led to a significant increase in most of these patients' hydroxychloroquine blood 
concentration [17]. The physician-patient relationship plays a crucial role in patient adherence to medication in SLE [33]. A strong working alliance, which sets treatment goals and tasks that are agreed upon between the provider and the patient, was correlated with increased adherence to medication in SLE [33]. Patient adherence to medication is a pervasive problem that continues to be tackled and overcome in patients with SLE.

\section{DISCUSSION}

Poor adherence is a huge problem in dermatology, and it is an especially difficult in chronic diseases [19]. Such diseases in dermatology such as acne and psoriasis have been extensively studied with regard to treatment adherence [34-36]. Despite its chronicity and impact on QoL, CLE has not been studied to nearly the same extent.

Accurately assessing medication adherence in patients with CLE and SLE is of great importance because doing so can distinguish patients who are non-responsive from those who poorly adhere to treatment [12]. This can prevent poorly adherent patients from being placed on more toxic medications [12]. Among the methods used in monitoring adherence to treatment in SLE and CLE, measuring hydroxychloroquine concentrations in the blood and utilizing MEMS stand out as potential methods of gauging treatment adherence; however, its use is mainly limited to clinical studies [29]. MEMS also allows for determining the time and date the medication was used, which is a feature that none of the other methods used can offer, and it allows for deeper insight into the specific adherence patterns that patients exhibit [29].

The long half-life of hydroxychloroquine makes blood levels a useful tool for assessing adherence [15]. Patients tend to take their medications more consistently around the time of office visits [19], limiting the value of blood levels for drugs with short half-lives. Several means of improving adherence to treatment in SLE were also investigated. The doctor-patient relationship can be used to improve adherence by engaging patients with adherence problems in a non-threatening way and discussing treatment characteristics. Creating a strong working alliance between patients and providers is another way the doctor-patient relationship can improve adherence to medication [33]. Text message reminders did not boost adherence to treatment [16]. Additional studies investigating how adherence to treatment can be further improved are warranted.

The majority of what is currently known about adherence to treatment in CLE is based on studies done on patients with SLE [37]. While there is significant overlap between SLE and CLE, only two SLE studies mentioned cutaneous manifestations. Of the two studies, OliveiraSantos et al. [14] noted that the presence of mucocutaneous manifestations of SLE was associated with decreased rates of adherence. The other study conducted by CostedoatChalumeau et al. [15] in 2006 noted that rashes were one of the findings associated with disease flares in patients with poor adherence to hydroxychloroquine. The rest of studies failed to mention what portion of SLE patients in their study were suffering from cutaneous disease, which leads to further difficulty in utilizing the results of these studies to further our knowledge of adherence in CLE patients, and in those with SLE suffering from cutaneous disease. While this could be viewed as a limitation of our study, it also demonstrates the current need for studies examining the impact of cutaneous disease on adherence in patients with SLE. However, it is 
likely that many (if not all) of these studies were comprised of patients with cutaneous disease, since the majority of patients with SLE will suffer from some sort of cutaneous manifestation of their disease at some point [10].

The study conducted by Frances et al. [12] was one of the two studies we found that investigated adherence to treatment in patients specifically with CLE. This study only examined adherence to hydroxychloroquine which is a medication that is taken orally. The other study [13] investigated adherence to sunscreen. However, no studies mentioned adherence to topical medications in treating CLE or cutaneous disease in patients diagnosed with SLE. While systemic therapy is essential in controlling more severe disease, topical and localized treatments are often used in the treatment of CLE and cutaneous manifestations of SLE [3]. This lack of knowledge is especially disconcerting because adherence to topical medications is lower than that of systemic medications [38, 39].

\section{CONCLUSION}

Much of what we know about adherence to medication in patients with lupus is limited to SLE. Although cutaneous symptoms are among the most common manifestation of SLE, cutaneous disease is often managed at least in part with topical agents, and adherence to topical treatment was not assessed in any of the articles, though one study investigated sunscreen usage in patients with CLE. Understanding adherence in patients with CLE may help contribute to better CLE treatment outcomes. Further studies are required to expand our knowledge of adherence to both topical and systemic medications in patients with CLE and cutaneous manifestations of SLE.

\section{ACKNOWLEDGMENTS}

No funding or sponsorship was received for this study or publication of this article. All named authors meet the International Committee of Medical Journal Editors (ICMJE) criteria for authorship for this manuscript, take responsibility for the integrity of the work as a whole, and have given final approval for the version to be published.

Conflict of interest. The Center for Dermatology Research is supported by an unrestricted educational grant from Galderma Laboratories, L. P. Dr. Feldman is a speaker for Janssen and Taro. He is a consultant and speaker for Galderma, Stiefel/GlaxoSmithKline, Abbott Labs, Leo Pharma Inc. Dr. Feldman has received grants from Galderma, Janssen, Abbott Labs, Amgen, Stiefel/GlaxoSmithKline, Celgene and Anacor. He is a consultant for Amgen, Baxter, Caremark, Gerson Lehrman Group, Guidepoint Global, Hanall Pharmaceutical Co Ltd, Kikaku, Lilly, Merck and Co Inc, Merz Pharmaceuticals, Mylan, Novartis Pharmaceuticals, Pfizer Inc, Qurient, Suncare Research and Xenoport. He is on an advisory board for Pfizer Inc. Dr. Feldman is the founder and holds stock in Causa Research and holds stock and is majority owner in Medical Quality Enhancement Corporation. He receives Royalties from UpToDate and Xlibris. Dr. Huang is a consultant for XOMA. He has conducted research studies for XOMA, Merz, and Keranetics. He has been a speaker for XOMA and Galderma. Dr. Huang is a consultant for XOMA. He has conducted research studies for XOMA, Merz, Roche, and Keranetics. He has been a speaker for XOMA and Galderma. Mr. Farhangian declares no conflict of interest. 
Compliance with ethics guidelines. This article is based on previously conducted studies and does not involve any new studies of human or animal subjects performed by any of the authors.

Open Access. This article is distributed under the terms of the Creative Commons Attribution Noncommercial License which permits any noncommercial use, distribution, and reproduction in any medium, provided the original author(s) and the source are credited.

\section{REFERENCES}

1. Verma SM, Okawa J, Propert KJ, Werth VP. The impact of skin damage due to cutaneous lupus on quality of life. Br J Dermatol. 2014;170(2):315-21.

2. Ezra N, Jorizzo J. Hydroxychloroquine and smoking in patients with cutaneous lupus erythematosus. Clin Exp Dermatol. 2012;37(4):327-34.

3. Chang AY, Werth VP. Treatment of cutaneous lupus. Curr Rheumatol Rep. 2011;13(4):300-7.

4. Benner JS, Glynn RJ, Mogun H, Neumann PJ, Weinstein MC, Avorn J. Long-term persistence in use of statin therapy in elderly patients. JAMA. 2002;288(4):455-61.

5. Richards HL, Fortune DG, O'Sullivan TM, Main CJ, Griffiths CE. Patients with psoriasis and their compliance with medication. J Am Acad Dermatol. 1999;41(4):581-3.

6. Carroll CL, Feldman SR, Camacho FT, Manuel JC, Balkrishnan R. Adherence to topical therapy decreases during the course of an 8-week psoriasis clinical trial: commonly used methods of measuring adherence to topical therapy overestimate actual use. J Am Acad Dermatol. 2004;51(2):212-6.

7. Conlon NP, Edgar JD. Adherence to best practice guidelines in chronic spontaneous urticaria (CSU) improves patient outcome. Eur J Dermatol. 2014;24(3):385-6.

8. Torrelo A, Ortiz J, Alomar A, Ros S, Pedrosa E, Cuervo J. Health-related quality of life, patient satisfaction, and adherence to treatment in patients with moderate or severe atopic dermatitis on maintenance therapy: the CONDA-SAT study. Actas Dermosifiliogr. 2013;104(5):409-17.
9. Zschocke I, Mrowietz U, Karakasili E, Reich K. Non-adherence and measures to improve adherence in the topical treatment of psoriasis. J Eur Acad Dermatol Venereol. 2014;28(suppl 2):4-9.

10. Rothfield N, Sontheimer RD, Bernstein M. Lupus erythematosus: systemic and cutaneous manifestations. Clin Dermatol. 2006;24(5):348-62.

11. Hochberg MC. Updating the American College of Rheumatology revised criteria for the classification of systemic lupus erythematosus. Arthritis Rheum. 1997;40(9):1725.

12. Frances C, Cosnes A, Duhaut P, Zahr N, Soutou B, Ingen-Housz-Oro $S$, et al. Low blood concentration of hydroxychloroquine in patients with refractory cutaneous lupus erythematosus: a French multicenter prospective study. Arch Dermatol. 2012;148(4):479-84.

13. Gutmark EL, Lin DQ, Bernstein I, Wang SQ, Chong BF. Sunscreen use in cutaneous lupus erythematosus patients. Br J Dermatol. 2015.

14. Oliveira-Santos M, Verani JF, Klumb EM, Albuquerque EM. Evaluation of adherence to drug treatment in patients with systemic lupus erythematosus in Brazil. Lupus. 2011;20(3):320-9.

15. Costedoat-Chalumeau N, Amoura Z, Hulot JS, Hammoud HA, Aymard G, Cacoub P, et al. Low blood concentration of hydroxychloroquine is a marker for and predictor of disease exacerbations in patients with systemic lupus erythematosus. Arthritis Rheum. 2006;54(10):3284-90.

16. Ting TV, Kudalkar D, Nelson S, Cortina S, Pendl J, Budhani $S$, et al. Usefulness of cellular text messaging for improving adherence among adolescents and young adults with systemic lupus erythematosus. J Rheumatol. 2012;39(1):174-9.

17. Costedoat-Chalumeau N, Amoura Z, Hulot JS, Aymard G, Leroux G, Marra D, et al. Very low blood hydroxychloroquine concentration as an objective marker of poor adherence to treatment of systemic lupus erythematosus. Ann Rheum Dis. 2007;66(6):821-4.

18. Zeller A, Ramseier E, Teagtmeyer A, Battegay E. Patients' self-reported adherence to cardiovascular medication using electronic monitors as comparators. Hypertens Res. 2008;31(11):2037-43.

19. Osterberg L, Blaschke T. Adherence to medication. New Engl J Med. 2005;353(5):487-97.

20. Mosley-Williams A, Lumley MA, Gillis M, Leisen J, Guice D. Barriers to treatment adherence among African American and white women with systemic 
lupus erythematosus. Arthritis Rheum. 2002;47(6):630-8.

21. Nived $O$, Andersson $M$, Lindgren $M$, MalcusJohnsson P, Nihlberg A, Nived K, et al. Adherence with advice and prescriptions in SLE is mostly good, but better follow up is needed: a study with a questionnaire. Lupus. 2007;16(9):701-6.

22. Koneru S, Kocharla L, Higgins GC, Ware A, Passo $\mathrm{MH}$, Farhey YD, et al. Adherence to medications in systemic lupus erythematosus. J Clin Rheumatol. 2008;14(4):195-201.

23. Julian LJ, Yelin E, Yazdany J, Panopalis P, Trupin L, Criswell LA, et al. Depression, medication adherence, and service utilization in systemic lupus erythematosus. Arthritis Rheum. 2009;61(2):240-6.

24. Chambers SA, Raine R, Rahman A, Isenberg D. Why do patients with systemic lupus erythematosus take or fail to take their prescribed medications? A qualitative study in a UK cohort. Rheumatology (Oxford). 2009;48(3):266-71.

25. Duvdevany I, Cohen M, Minsker-Valtzer A, Lorber M. Psychological correlates of adherence to selfcare, disease activity and functioning in persons with systemic lupus erythematosus. Lupus. 2011;20(1):14-22.

26. Daleboudt GM, Broadbent E, McQueen F, Kaptein AA. Intentional and unintentional treatment nonadherence in patients with systemic lupus erythematosus. Arthritis Care Res. 2011;63(3):342-50.

27. Marengo MF, Waimann CA, de Achaval S, Zhang $\mathrm{H}$, Garcia-Gonzalez A, Richardson $\mathrm{MN}$, et al. Measuring therapeutic adherence in systemic lupus erythematosus with electronic monitoring. Lupus. 2012;21(11):1158-65.

28. Gross R, Graybill J, Wahezi D, Jordan NC, Putterman C, Blanco I. Increased Education is Associated with Decreased Compliance in an Urban Multi-Ethnic Lupus Cohort. J Clin Cell Immunol 5(3). 2014.

29. Koneru S, Shishov M, Ware A, Farhey Y, Mongey $\mathrm{AB}$, Graham TB, et al. Effectively measuring adherence to medications for systemic lupus erythematosus in a clinical setting. Arthritis Rheum. 2007;57(6):1000-6.
30. Abdul-Sattar AB, Abou El Magd SA (2014) Determinants of medication non-adherence in Egyptian patients with systemic lupus erythematosus: Sharkia Governorate. Rheumatol Int. 2014.

31. Chambers S, Raine R, Rahman A, Hagley K, De Ceulaer $\mathrm{K}$, Isenberg $\mathrm{D}$. Factors influencing adherence to medications in a group of patients with systemic lupus erythematosus in Jamaica. Lupus. 2008;17(8):761-9.

32. Nery FG, Borba EF, Hatch JP, Soares JC, Bonfa E, Neto FL. Major depressive disorder and disease activity in systemic lupus erythematosus. Compr Psychiatry. 2007;48(1):14-9.

33. Bennett JK, Fuertes JN, Keitel M, Phillips R. The role of patient attachment and working alliance on patient adherence, satisfaction, and health-related quality of life in lupus treatment. Patient Educ Couns. 2011;85(1):53-9.

34. Thorneloe RJ, Bundy C, Griffiths CE, Ashcroft DM, Cordingley L. Adherence to medication in patients with psoriasis: a systematic literature review. $\mathrm{Br} \mathrm{J}$ Dermatol. 2013;168(1):20-31.

35. Snyder S, Crandell I, Davis SA, Feldman SR. Medical adherence to acne therapy: a systematic review. Am J Clin Dermatol. 2014;15(2):87-94.

36. Ou HT, Feldman SR, Balkrishnan R. Understanding and improving treatment adherence in pediatric patients. Semin Cutan Med Surg. 2010;29(2):137-40.

37. Costedoat-Chalumeau N, Pouchot J, GuettrotImbert G, Le Guern V, Leroux G, Marra D, et al. Adherence to treatment in systemic lupus erythematosus patients. Best Pract Res Clin Rheumatol. 2013;27(3):329-40.

38. Krejci-Manwaring J, McCarty MA, Camacho F, Carroll CL, Johnson K, Manuel J, et al. Adherence with topical treatment is poor compared with adherence with oral agents: implications for effective clinical use of topical agents. J Am Acad Dermatol. 2006;54(5 Suppl):S235-6.

39. van de Kerkhof PC, de Hoop D, de Korte J, Cobelens SA, Kuipers MV. Patient compliance and disease management in the treatment of psoriasis in the Netherlands. 2000;200(4):292-8.
Dermatology

(Basel). 